\title{
Academic Publishing and Open Access: Costs, benefits and options for publishing research
}

\author{
Christopher May \\ Professor of Political Economy, Lancaster University, UK \\ Email: c.may@lancaster.ac.uk
}

For many years I researched the international/global political economy of intellectual property rights, looking at how the narratives of justification around copyright, patents and other intellectual properties varied from the real world political economy of making property out of knowledge. One aspect of this issue (and indeed the intellectual property issue that academics and researchers are most often aware of) is how we (which is to say the academic community) have organised the publication (and thereby formal communication) of the results of our work. In this article I focus primarily on academic journals, as while there are parallel issues in the publication of books, this aspect of publishing currently seems less fraught or problematic for the university research community. ${ }^{1}$ It is also clear that there is some disquiet about the operation of peer review as part of the academic publishing process, but while this can impact on researchers' ability to get their work published for reasons of space I have left a discussion of reforming peer review to others. ${ }^{2}$

Rather, this article focusses on the development of open access as an alternative to the traditional model of academic publishing, and in doing do returns (again) to a theme I have explored before. Given the advent of Plan S (see a later section) alongside the slow uptake of open access by politics and international relations (PIR) scholars, it seemed like a good time to again pose the question, to my senior colleagues, but also to early career researchers brought up in a world where free-toview content (via social media) seem ubiquitous: why are we not publishing via open access routes more often? In this sense this article is intended as a provocation!

Writing in European Political Science in 2005, I concluded my assessment of the then current state of open access publishing in PIR by suggesting, that given that much of the substance of scholarly reputation is related to citation rates, if we were/are really interested in re-shaping the political economy of academic publication then we needed to seek out open-access sources to cite for ideas we wish to engage with, rather than relying on the journals controlled by commercial academic publishers (May 2005). Some, eight years later, writing for e-International Relations, I suggested that it remained unclear 'how readers might judge the quality and/or value of what is available on-line, given the academy practically lacks confidence in open access' (May 2013). While there had been some significant changes to everyday practices in the academy much of the standard model of academic publishing remains stubbornly in place.

\footnotetext{
${ }^{1}$ This paper was originally delivered as the keynote address at Selling (critical) finance: Getting your work published. Early Career Researcher Workshop, 3rd - 4th September 2018, University of Warwick, UK. This expanded and revised version benefitted greatly from the engagement of the referees, and I thank them for their suggestions and disagreements that allowed me to more clearly focus my argument.

${ }^{2}$ See for instance the discussion of alternatives to peer review in the humanities in Eve (2014: chapter five).
} 
Therefore, this article briefly sets out a political economy of academic publishing, which in the UK at least paralleled the significant expansion of both the number of universities that supported research by their staff (organisationally and financially) and, also especially in the last couple of decades, the growth in form(s) of oversight and management of research 'quality'. This leads me to say something about what the costs and benefits of this model are/were before exploring the forms of open access publication available to the social science (and specifically PIR) community in the UK and beyond while also briefly setting out one recent and important political innovation (Plan S). I conclude by asking why (given its likely advantages) the open access model is not ubiquitous, briefly speculate why researchers in politics have been reticent in their adoption of open access and suggest that the future of publication lies our hands.

\section{A political economy of academic/scientific publishing}

The (now) standard model of academic publishing finds its origins in Robert Maxwell's Pergamon Press which was an early mover in recognising that the expansion of university research would also lead to an expansion in the demand for the dissemination of results. Moreover, seeing the commercial competition raise the production standards of journals, many non-profit professional and disciplinary associations decided their interests were best served by selling their journals to the new arrivals in the market (Buranyi 2017). Perhaps the key insight that Maxwell had (and which was then picked up by his successors) was that the generation of academic knowledge would expand to meet any increase in journals (even if they were essentially complementary in focus) and that academics (having no need to pay for the journals themselves) would stoke demand by ordering subscriptions for their institution's library. ${ }^{3}$ Maxwell and those who followed him were able to construct a form of market intermediation where it had hitherto been under-developed or even non-existent.

Indeed, this move to commercialise an intellectual resource might be regarded as a new form of enclosure (to use a phrase popular in the discussion of the reach of intellectual property at the turn of the millennium) or as a form of primitive accumulation (Glassman 2006; Perelman 2000; Sassen 2010). The latter analysis would identify a social resource which was largely produced by communities without any market logic, with little regard for profitable exchange or transfer as a driver of supply. These resources are then (as with all primitive accumulation) brought into capitalist market relations as 'natural' resources for processing, being regarded as unowned and having been divided off from their originators or self-identified 'guardians' (sometimes violently). These are then rendered as commercial products by the mediation of capital and sold on for profit, thereby facilitating the accumulation of capital without incurring costs for a significant input. As will become clear, one might argue that unlike most 'normal' primitive accumulation, here the originators enter the process voluntarily and rather than being unowned, the resources passed to publishers are subject to a formal transfer of ownership at the point of acceptance. How voluntary this involvement is, however, is reflects an assessment of the

\footnotetext{
${ }^{3}$ See Fyfe et al (2017) for an excellent and concise overview of the history of academic publishing that complements and extends Buranyi's (2017) more popular (albeit well researched) treatment.
} 
possibility of having an academic career without publishing in such journals; not impossible, but increasingly unlikely.

So, the political economy we are familiar starts with a range of inputs produced by academic staff and researchers who are paid by universities to research and communicate their findings in addition to any teaching commitments that they may have. While the institutional political aspects of this function have certainly shifted towards surveillance and managerialism, even before the formalisation of the assessment of research, most academics produced research-related content as part of their professional practice and associated attention to their careers. Thus, a key economic input for academic publishers is not produced for an economic profit (by sale to the processor) but rather is part of a wider scholarly endeavour that is commercialised by the publishers as part of its progress towards dissemination. While publication of books involves a (real if often paltry) cost in royalties paid for content, for journal publishing this input cost is almost completely avoided, despite academic content being the cornerstone of the business. This of course is the key fissure in the model, to which we will return; if as Stephen Buranyi (2017) estimated, this is a saving of around $12-15 \%$ (the rate of input total costs associated with publishing in other sectors of the industry), the profitability of academic publishing comes into focus a little more clearly.

This content is then assessed, edited and prepared for publication by a usually unpaid sub-group of the academic community (journal editors, peer reviewers) working with editorial staff in publishing companies. Once reviewed (and revised) this content is rendered into publications, ranging from journal content/articles, to chapters in edited collections and academic monographs. In the past the technologies of publishing, transforming articles into publishable forms (typesetting, dealing with proofing amendments) and the print distribution indicated a clear contribution of publishers to the process; this largely remains the case with book publishing, even if authorial input at the proofing stage allows publishers to effectively de-skill elements of their production process. For journals, however, the input/contribution provided by the publishers has been subject to various critiques including questions about subscription prices and editorial bias. Most publishers continue to make a claim for a contribution around type-setting and the organisation (if not the actual practice) of peer review; they also will suggest that they are able to market the journal to extend its disciplinary (and international) reach in a way its editorial team would find impossible acting alone. However, digitalisation and the wide availability of various new publishing technologies have to some extent undermined the argument that publishers' expertise might add value.

Academic journals have been and remain almost always aimed at university libraries who subscribe on the basis of recommendations, expressed pedagogic need and the disciplinary standing of the journal. Most large publishers now expect (need) to sell bundles of subscriptions to ensure that libraries (seeking to limit subscription-related financial exposure) cannot ask academics who are seeking a new subscription to nominate a journal to cancel (in the past a common practice). Bundles (or aggregation) make that difficult, but also ensures for new journals (which can be added to a bundle), an immediate institutional 'demand' if the journal is included in a bundle. Books are often also aimed at the university library market but there is potentially a cross-over into a more general 'trade' market for some titles with 
general appeal (or which are more widely marketed). Moreover, while books have some of the same pricing issues, the availability of different formats, hardback, paperback and e-book, has allowed a level of differential pricing that for now at least seems to have drawn much less criticism, even if the pricing issue remains potentially problematic in some disciplines.

It is clear even from this brief analysis that there is a certain circularity in academic publishing (which has been the grounds for significant recent criticism): research in universities (paid for by the universities themselves or research funders) produces outputs, that are rendered into academic publications that are then purchased by universities, in an often reasonably closed ecosystem (few academic publications secure extensive sales beyond the university sector). This has led to a common accusation that publishers are profiting twice (from cheap/free inputs and from charging for subscriptions and/or access rights); the university sector is paying twice to support commercial publishing houses.

\section{The costs and benefits of 'normal' academic publishing}

Perhaps the clearest benefit of the standard model of academic publishing is that there is an independent organisation (the publisher) who acts as a gate-keeper to the public realm, assuring quality. Certainly one might argue that the university presses and professional associations that manage publishing programmes are not independent from the university community, but even here the modes of operation that are adopted are intended to establish this separation. This independence can work especially well for publishers where the 'benefit' to the academic community is the establishment of a particular journal as the one where anyone who is anyone must publish (David 2017:89). Indeed as Christopher Merrett put it some years ago:

Publishers pull off this confidence trick (the massive subsidisation of the publishing industry by government and other education funders) by understanding only too well the fissures, faults and inherent vulnerability of academic life (Merrett 2006: 97).

The benefit to the academic community is the inoculation of the maintenance of a relatively clear journal hierarchy from accusations of self-interest or bias. The individual academic whose work in the system is for the most part unpaid, often does believe (not unreasonably) that there is a likelihood that the benefit of such work will 'cash out' in career advancement either by strengthening the CV in the process of obtaining a new (or different) job, or in promotion in their own institution.

However, while the benefits are therefore largely diffused and community-based, the costs of the current model are mainly financial and as noted above represent a significant double charging for research communication. The research community supports the production of new research and its associated outputs through salaries and grants; this knowledge is then processed into a publishable form by academic publishers; and then universities pay again to secure access to the research outputs for libraries. How large a net cost this is to the university sector is a matter of assessing how valuable the intermediate stage conducted by publishers is? While the benefit of gate-keeping and the establishment of authority for outputs clearly has some value to the academy, does this balance the costs to a reasonable extent? Crucially, of course, the publishers actually hold little academic expertise themselves; where critical judgements are required on quality, while often paid (or 
partly paid) these are drawn from the academy (Pirie 2009: 40). Although the gatekeeping/quality function is important, other than by convention it is difficult to see what academic publishers now contribute in addition to the funds for the production of outputs (which are in any case drawn from their charges to universities, which generate the gross profits of the sector).

Conversely, it is clear that for publishers the standard (current) model has significant advantages/benefits; it delivers high quality content (reviewed and 'improved' by the academic community) ready to be published (David 2017: 111). Collectively the academy provides, through its staff and students and library purchases, the majority of the market for such work (with the exception of those colleagues whose work had gained a more general traction in the book market). Moreover, the oligopolistic concentration among the five major publishers in the social sciences - ReedElsevier, Wiley-Blackwell, Sage, Springer, and Taylor \& Francis - reaching between $60 \%$ and $80 \%$ of all journal articles published in some disciplines, has consolidated the market control of this group (and thereby, unsurprisingly, enhanced their profitability). The highly concentrated character of the academic publishing sector (in journals if much less so in books) means that the major journal publishers enjoy 'super profits' regularly between $25 \%$ and $35 \%$ on operations (Larivière, Haustein \& Mongeon 2015), far beyond what Amazon, Google or Facebook manage in percentage terms. Even if we accept that the intermediate stage has a significant benefit to which can be afforded monetary value, it seems unlikely its social value is so much greater than other sectors also working in knowledge dissemination of one sort or another to legitimise these levels of profitability.

One further transformation has been brought about by publishers' move to digitalised outputs; the (sometimes un-noticed) shift from a model of purchase (with some copyright-related constraints on re-use) to a model of licenced use and the end of any final purchase of the output; access to journal archives are generally part of the license agreement, are not 'owned' by university libraries and thus remain contingent on continued payments. By manipulating stand-alone journal subscription prices, the large presses have 'encouraged' libraries to buy package deals. One advantage of this model as noted above is that it presents a less risky environment for the launch of new journals, which (if published by an aggregating publisher) can survive on much lower individual subscriptions (Phillips 2009: 89-90). The up-front investment in launching a new journal can be recovered more quickly, and for the aggregators this also erects a significant barrier to entry for independent publishers (as regards the standard model at least). However, journal subscription aggregation or bundling, also reinforces the companies' oligopolistic domination of the market and thereby their profits.

This leads to at least two major problems with the digitised aggregation model that are increasingly obvious to librarians and academics: the loss of control over the shape of the libraries overall stock of journals; and the lock-in that this causes through the academic interest in retaining access to archives and back-issues (Merrett 2006: 101). Whereas in the past the proprietary model was circular, returning scholarly knowledge to the ownership of universities (once it had been through the publication process) albeit with some (limited) copyright-related caveats on use, the move to digitalisation and licencing is something different, the capture of a resource that is then rented back to the originators. This is to say the (digital) 
publication of academic journals has become patterned by the private appropriation of (quasi-) public (knowledge) resources (Pirie 2009); as argued above it is increasingly a form of primitive accumulation. It is the growing recognition of this shift in the terms of trade (and ownership dynamics) in academic publishing that has prompted the growing interest in open access publication of various sorts. ${ }^{4}$

\section{The open access alternative(s)}

The key structural element of the standard publishing model is the rendering of research content as intellectual property controlled by the publisher (having 'requested' its transfer from the author in the contract for publication), and by doing so allowing a fee to be extracted for its (re)supply into the academy. This reliance on intellectual property has in the last two decades been confronted with a different model for understanding how knowledge enters the public realm, as championed by the global campaign Access to Knowledge (A2K). This campaign is largely concerned with the global access to scientific knowledge and has mostly focussed on issues around the costs of technology transfer to developing countries (to aid their economic development strategies) and the constraints on health-related knowledge diffusion which if freely accessible might raise welfare across the global system. ${ }^{5}$ In addition to these big and highly politicised issues, there has also been some concern about the impediments to the circulation of the results of academic research caused by the standard subscription and charging models that have patterned academic publishing.

This interest has led to significant discussions about how access to academic research outputs might be best widened and as such open access has become the focus of considerable attention. In the academic community this has solidified into a two level model of what open access might entail. Thus, as defined by the Higher Education Funding Council of England, the major forms of open access are:

- Gold - This means publishing in a way that allows immediate access to everyone electronically and free of charge. Publishers can recoup their costs through a number of mechanisms, including through payments from authors called article processing charges (APCs), or through advertising, donations or other subsidies.

- Green - This means depositing the final peer-reviewed research output in an electronic archive called a repository. Repositories can be run by the researcher's institution, but shared or subject repositories are also commonly used. Access to the research output can be granted either immediately or after an agreed embargo period. ${ }^{6}$

This raises some interesting questions: once open access modes have been settled on, where will these knowledge resources be located? How might they be accessed? How are the (necessary?) costs of production of the published output to be met? It is also now clear, that major European research funders saw the inclusion of the Green

\footnotetext{
${ }^{4}$ Space precludes the development of the argument that this business model for digital publication represents the impact of financialisation on academic publishing, but certainly this would be a relatively easy argument to make.

${ }^{5}$ See (appropriately) the movement's entry on wikipedia:

https://en.wikipedia.org/wiki/Access to Knowledge movement (07.08.2018)

${ }^{6}$ HEFCE 'Open Access Research: Policy Guide - What is open access?'

http://www.hefce.ac.uk/rsrch/oa/whatis/ (07.08.2018)
} 
route in such statements as merely a stepping stone to the full Gold route envisaged (now) by Plan $S$ (see next section).

The move to the Gold model may actually accelerate, if the incentives to publish in key Gold open access journals strengthen as the associated academic norms shift, allowing publishers to raise publication fees. Therefore, while initially reticent about the Gold model, publishers have now embraced the model as it may be an opportunity for large multinational publishers to further enhance their oligopoly. That said, and reflected in the concerns about hybrid journals in Plan S (see below), the large publishers have also sought ways to control access by allowing Green depositories, likely in the view that actually accessing these open access depositories is insufficiently easy for readers that they will prefer the 'real' journal publication. This has also led to the identification of 'bronze' publication, which appears to have the attributes of openness but does not formally utilise open licencing, thereby making open access both contingent and less robust than under the standardised arrangements (Costello 2019). Moreover, John Holmwood has argued that the work undertaken by scholarly and learned societies and other nonprofits to support a mixed and complex ecology of journals in social sciences and humanities could be threatened by a move to an open access mono-culture (Holmwood 2018), especially if these developments do not solve the search/access problem of making clear where the work can be accessed - currently a functionality seemingly implicitly passed to Google Scholar.

For the publishers, then the Green route (and its bronze variant) is generally seen as an add-on to the standard model, allowing publishers to retain the final output (sometimes for an agreed embargo period) while pre-print (non-typeset) versions are available, but remain less easy to cite due to missing page numbers and lack of full publication details (metadata) (sometimes referred to as the hybrid model). However, the growing levels of non-cooperation in this solution (as discussed below), have prompted publishers to explore the Gold route. This pay to publish model of open access is also relatively undisruptive to the publishers, but requires a significant shift in perspective from funders and universities; research funders and/or universities pay for a journal's publication costs up-front via APCs allowing the work to be freely distributed and by doing so making the payment to the private sector for their contribution to the process absolutely explicit. If widely adopted APCs, in the long run, may cause the subscription model to wither on the vine as more and more work is published outside that model. However, there remains some difficulty around 'unfunded' research, especially prevalent in the social sciences \& humanities, which either needs to be paid for by the home institutions, remain published in the old (standard) subscription model, or move to a much more radical (purer) version of open access, with the range of reputational issues that this might then encompass.

Most universities now operate some form of institutional depository for open access to work published elsewhere (the Green route), along with a form of e-print function for working papers and other in-process outputs. Less developed, at the moment at least, is the possibility of repositories organised around disciplines, perhaps maintained by professional associations. Here, one can see that there is the possibility for retaining a peer review element that would allow the repository to act in some ways as a parallel to journal publication (Shreeves 2009). Certainly some research centres and think-tanks with strong academic links have already gone 
some way down this route. For instance the Sheffield Political Economy Research Institute (SPERI) has a well-regarded and wide range of publications, free to access, including much recent academic research. ${ }^{7}$ Publicising the holdings of an Universitybased depository, on the other hand, might be a challenge as the holding of a (relatively) full spectrum institution would be so varied that it may only be the author themselves who can effectively publicise the availability of a specific paper to the relevant audience on a case by case basis. For the disciplinary repository this is less difficult as many professional associations already have the experience of publicising and communicating the contents of proceedings and their own journals. One suggested open access strategy then, if as yet relatively under-developed in the social sciences, is for professional associations to run peer-reviewed disciplinary focussed repositories, either in parallel or in addition to the 'normal' academic journal publication route.

Pragmatically, on the other hand, many academics seem to have taken things into their own hands by using a number of services on offer, all of which in one way or another have an ambivalent relationship with copyright law(s). This has, as noted, led to some disquiet about the Green model as work (in published form) appears in academic networks outside the control of the publishers, and undercuts the charging structure(s) of the Gold model. Perhaps the best example of this bottom-up academic strategy has been the expansion and utilisation of Academia.edu - a forprofit corporation that has adopted a relatively standard 'freemium' platform economy model. Academia.edu has a standard free service and a premium service which is marketed (quite cleverly) as providing enhanced data and functionality, but also as a way premium subscribers can support the utility of the free service to the global academic community. Currently its service to over 72 million subscribers is supported by 107,000 subscribers, and hosts by one estimate around $20 \%$ of all academic papers ever published, while its investors (including Tencent from China) adopt the usual wait for scale approach of many internet start-up backers (Fortson 2019). There have been some disputes about what is circulated - post-publication PDFs are frequent - and also some disquiet among users about the extent of the forprofit aspects of the service. Nonetheless, Academic.edu offers an interesting model of how a bottom-up form of open access might develop further, although it still remains at the margins of career development. This might change it if article/paper download statistics became important to institution's promotions committees as an indicator of academic standing. However, if Toby Green is correct and $80 \%$ of published articles stubbornly remain behind paywalls (Green 2018; see also Fortson 2019) then the question is why have academics not taken up open access in anything other than a marginal way?

\section{Plan S: one (possible) future for academic publishing}

Plan S is a European initiative launched in late 2018, led by Robert-Jan Smits, the European Commission special envoy on open access and organised through Science Europe/cOAlition S (an association of European research councils and funders of scientific research, more recently joined by the Welcome Trust and The Gates Foundation), and supported by the Association of European Research Libraries and other groups interested in promoting open access. The initiative is

\footnotetext{
${ }^{7}$ See: http://speri.dept.shef.ac.uk/publications/
} 
intended to require all publically funded (scientific) research to be published via open access routes after 2020. According to analysis published in Nature as currently conceived this would bar publically funded researchers from publishing in around $85 \%$ of scientifically focussed journals (Else 2018; see also Kwon 2018).

The plan's key elements are encompassed in its ten principles which require, that authors retain (unencumbered) copyright in their publications and release them under a creative commons licence; the establishment of clear and robust criteria to designate what open access is; incentives to develop open access outlets in (sub)disciplines where none exist currently; a default position that institutions and/or funders pay publication fees, not individual researchers; publication fees are standardised across Europe; that research institutions, universities and libraries should align their policies to maintain transparency about open access publication; the acknowledgement of the key role of open archives and repositories; that funders will monitor compliance; and (already subject to significant criticism) the assertion that a 'hybrid' model of publishing would not comply with these principles. While intended to cover all publication it is recognised mechanisms for monographs may take longer. $^{8}$

The criticism of the position on 'hybrid' publication has led to a swift if slight relaxing of this prohibition with a third open access route added to the initial two of open access journals or platforms, and open access repositories; being those 'hybrid' journals that have 'transformative agreements' in place. One posited response to Plan S' requirements was the potential development of 'mirror journals' that would be split into two (sharing editorial board and the same publication policies) but with one remaining a 'hybrid' journal and one being fully Plan S compliant, with authors offered on submission the choice of which path to submit their article to (Cochran 2018). The proposal depends on its acceptance by research funders, which is to say whether the mirror journal would be regards as sufficiently different to avoid the Plan $S$ prohibition prompted by a 'hybrid' journal with (as a result) no transformation undertaking in place, and that this model was not characterised as 'double dipping' in the (now) variegated subscription market. It also depends on technical issues such as the calculation of impact factors, the choice exercised by libraries when offered such subscription choices and whether (as Angela Cochran expects) this would eventually prompt the non-open access component to wither on the vine.

Another early response to the plan from the International Association of Scientific, Technical and Medical Publishers (representing around 150 publishers) focussed their criticism on the potential 'unintended limitations on academic freedoms' while other critics have identified costs of publication as a potential problem for researchers outside Europe (and by implication those within that lack public funding) (Else 2018). Indeed, as this is a regional initiative, it impact on the main academic publishers is likely to be uneven, not least as while some European research clearly has a global impact, much remains focussed and read in the regions in which it is published. It is (as yet) unclear what modes/routes would be put in place to ensure non-European (developing country) research, which for many reasons, not least academic career management might be best published in Europe, was still able to access journal publication.

\footnotetext{
${ }^{8}$ The principles and supporting material can be found at: https://www.coalition-s.org/10-principles/
} 
This major but as yet far from settled move in science has generated significant early engagement from both the academy and from publishers leading already to clarification, and, as noted, a modicum of relaxation of the planned requirements (Kwon 2018). While these debates will continue as the plan develops, it is worth noting that Plan S explicitly includes other disciplines, with a direct statement that science includes the humanities in its call for open access. Might the high profile coverage of Plan S move academics in politics and its related disciplines to consider open access (more than they have already)? In criticising Plan S as doing little to reduce the domination of large multinational publishers, Brian Cody has argued the real open access future lies with initiatives that are rooted in the academic community not the publishing industry (Cody 2018). Before exploring this possibility in the final section, first I want to reflect on why open access publication is not already more widespread in politics.

\section{Why is open access academic publishing in politics not ubiquitous?}

Recent research by University of Utrecht's library researchers, published in the Innovations in Scholarly Communication, demonstrated that while around half of all journals (on the web of science) in public administration or international relations (which I have taken jointly as a proxy for PIR) offered some form of green open access (see above) with a small minority offering gold, the take-up of these options from these hybrid journals was around $10 \%$ of published work (Kramer and Bosman 2018; see also Carling et al 2018 which uses different data to reach a similar figure).

One way of understanding the (relative) lack of use of open access alternatives to publishing with journals published by the 'big five' in social sciences is to utilise an analysis focussing on academic literacies. This recognises that decisions about choosing forms of outputs and (publishing) locations are driven by a range of factors including both the desire to share work, and the development or maintenance of a researcher/author's reputation or profile (Nygaard 2017). While the acceptability of open access publications may be growing, the reputational benefits claimed by the big five still factor into many decisions about where to publish. In a world of research data monitoring where citation is a key metric (including specifically, impact factors for journals), and where managerialism foregrounds such research productivity measures, movement away from the major journals in any field is likely to be slow. So, if researchers belong to a number different communities simultaneously (ranging from internal/institutional to national and global disciplinary communities), it is only when the assessment of research outputs by most of these groups clearly favours open access that the bulk of the most important work will be published this way. It is only when the shape of academic literacies shifts profoundly that we will see a significant move in publishing; it is not so much an issue of the availability of open access platforms, journals and opportunities but how they fit into (y)our own understanding of our academic lives.

Moreover, for any journal the early post-launch years can be difficult. As already noted, the standard model was (re)developed in such a way as to allow early costs to be (partly) covered by including a new journal in subscription packages. Prior to this, new journals were often loss-making for the first few years, where marketing and start-up costs were not covered by subscriptions (Phillips 2009: 89) adding to 
and supporting the claim of a publisher contribution to the academic community. However, even in open access models, there are start-up issues to resolve: primarily securing high quality content, establishing profile and becoming cited (as a measure of academic value), all of which incur costs in time (and money) even if we began a concerted move towards wider open access publication in politics. In addition, relative 'underperformance' in the academic environment (perhaps measured by low number of views/downloads, or lack of submissions) may in the end outweigh the (psychological and organisational) investment required by its managing editors.

Reiterating my conclusion some years ago, open access publishing is not ubiquitous in part because as academics we still have insufficient trust in this alternative system. This might seem slightly odd as the practice of academic publishing is not underwritten by commercial drivers, but rather is largely shaped by a generalised ethic of sharing; academic researchers in all fields develop and write journal articles, book chapters and monographs not to directly make a substantive financial return but rather to share their ideas (David 2017). Certainly, this sharing ethic may be itself shared only to some extent between colleagues, but in the main the explicit reasons for publishing (taking into account the career development aspects noted above) are the sharing of ideas, findings and analyses and seldom to make a significant income. This is where the academic literacies approach offers some clear guidance; recognising that the motives and expected benefits of publication are multidimensional, but systemically linked, and may be weighted differently between individuals as well as more generally between disciplinary communities.

This parallels the findings of Aileen Fyfe and her colleagues; they conclude their helpful historical survey of academic publishing thus:

[E]fforts to use the Web to create alternative, non-profit-driven models of academic publishing have been stymied by the inertia of the academic prestige culture. For valid historical and cultural reasons, academic systems of reward and recognition privilege the established forms of academic publication.... In the online world as in the printed world, publishing research with a familiar journal or press brings more prestige to its author; publishing in a new online journal or repository - as in a typescript journal in the 1960s - may be seen as a career risk

It would still take significant moral courage for a UK academic now to publish their work outside the traditional publishing structures, although there are variations between academic communities (Fyfe et al 2017: 16, emphasis added).

Interestingly in the humanities the oligopolistic concentration of journal publishing is nothing like as developed. This lack of big five domination may be the result of a number of factors, from the scale of publishing, to the lack of urgency in humanities research (Larivière, Haustein \& Mongeon 2015), but it might also be evidence of a variance in mores, citation practices and how reputation is built in the humanities and arts; academic literacies in humanities are different. In the humanities the source of record is more often the monograph rather than the scholarly article, and the access issues here are somewhat different and perhaps less controversial. Equally, as Martin Eve has discussed in humanities research reputation and prestige are key aspects of the choice of routes to publication, but these are largely related to the community of humanities scholars themselves (Eve 2014: 44-55). This, again, would seem to emphasise that the key ground for change would be any discipline's 
academic literacies. Drawing from Eve, and from the humanities, this indicates a need to expand cooperative and collaborative inter-institutional platforms that can deliver the reputational and symbolic pay-off of proprietary publication but outside (or parallel) to the current (largely) commercial system (Eve 2014: 68-76).

Therefore, without a change in the academic literacy of social sciences, as lan Pirie argued a decade ago: 'What is most plausible, without concerted political action, is that the system will suffer some erosion at the margins without its fundamental features being undermined' (Pirie 2009: 41). If so, it may be the case that as social science researchers, we should be looking at the humanities for suggestions of how prestige and reputation can be plausibly maintained outside (or alongside) commercial publishing, and therefore for ideas about how to positively reform our practices, and indeed with Academia.edu this erosion at the margins may already be more extensive than is necessarily clearly obvious to any particular discipline.

\section{The future for academics and researchers}

The shift to comprehensive open access publishing undoubtedly requires both institutional changes (by universities, as well as other research organisations, and publishers) and shifts in the research communities' academic literacies. What is perhaps most striking working in PIR is the relative reticence of colleagues to adopt open access options; while I have not undertaken any attitudinal surveying of academics working broadly in these fields, it seems clear to me that a couple of evident differences between academic literacies across disciplines may begin to explain the relative lack of interest in open access publication. Firstly, unlike many scientific disciplines, the dominant model of research activity seems more individualistic; while there are certainly collaborative projects in PIR these remain anomalous. This individuality does little to foster a culture of sharing work outside one's immediate socio-academic networks, other than in instrumental ways, to gather feedback for further improvement. Secondly, although much work in PIR is directly related to policy issues, the relative disconnect between the discipline(s), especially in the UK, and policy elites, renders much research and analysis as outsider critique. This may lead to a tendency (which I have certainly observed in my own networks) of a certain 'bunker mentality' which while leading to not-infrequent sharing of work-in-progress within the group, also can lead to a dismissal of those beyond the 'inner circle', again leading to a lack of interest in sharing work more widely via open access avenues. This reflects not so much a positive choice to avoid open access, but rather a disinterest in any wider community of interest. This suggests that for open access to become more common in PIR there needs to be a significant shift in the disciplines' academic literacies.

It is unlikely that either senior colleagues or early career researchers working alone can effect such a change. Indeed, studies cited in Carling et al (2018: 24) suggest that while in North America younger scholars were more likely to consider open access publication routes and established researchers were concerned about reputational risks, in Europe these positions were largely reversed with established scholars less worried as the risks seemed less evident later in an academic career. More crucially, for temporary staff, while the accessibility of their research may aid and support their career development, where access charges mean that publication support is only available to those researchers with longer (permanent) affiliation to 
their institution, the move to the model envisaged in Plan S may have a detrimental impact on their ability to benefit from the career-enhancing aspects of publication (Carling et al 2018: 36-37). As this indicates, the danger is a move to the Gold model of open access removes a paywall that constrains readers' access, but replaces it with another paywall between journal and author, with inequitable and prejudicial impact(s).

Moreover, as two recent European Union reports have stressed, the competitive character of academic careers, alongside the manner in which academic standing has been closely aligned with publication in key academic journals, has underpinned the continuing recourse to proprietary publication. Therefore, in different ways both reports focus on the incentive structure of European academia, with particular concern about the damaging influence of Journal Impact Factors on the choice of publication outlet for colleagues with any interest in career progression. While one report identifies a range of aspects in career assessment (from research outputs and practice, to leadership and training/mentoring), arranged across a matrix, which need to stress the foregrounding of 'openness' in all aspects of career evaluation (O'Carrol et al 2017), the other identifies key sets of actors from researchers and institutions to funders and other interested 'societal groups' who need to amend their practices, again to privilege openness (Guédon et al 2019). However, what is clear from both is that without clear incentives for academic communities to adopt different modes of assessing academic standing, moves to open access will remain slow and uneven. Therefore alongside any change in academic literacies at the disciplinary level, the management of the academy (peopled of course, mainly be academics) needs to wholeheartedly embrace openness, most specifically in promotion criteria and 'performance review'.

Nevertheless, there are reasons for guarded optimism: one of the key shifts that is discernible, and which is open to all academic staff regardless of career stage or institution, is the move to a stronger emphasis on the early, casual stages of communication of research findings, and analytical insights, through online media such a blogs, twitter or the highlighting of institutional depositories through social media signalling. This shift in balance between the early and later stages of formalisation of communication could be the way the standard model of journal publishing becomes less central, leaving (perhaps) the book as the final consolidation of previously communicated research elements which to some extent seems to be happening (on anecdotal evidence) in humanities. There may also be some advantage as regards the frequency of citation as in the humanities, although at present this seems to be relatively less likely in PIR (broadly conceived), but the situation is likely to be fluid (Atchison and Bull 2015). Such a move would reflect a pragmatic adoption of what I have called elsewhere 'Bounded Openness' (May 2011).

The idea of bounded openness starts from the position that openness is not a totalising model that 'changes everything' (as some enthusiasts claim); as a counterbalance to the closed logic of ownership, 'bounded openness' may be a better way to think about how academic publishing is developing. It better describes a project of openness that itself cannot comprehensive, because the erosion of ownership of knowledge may also bring with it the parallel erosion of confidence in the information that is accessed. Here, the increased visibility of citation metrics 
(both through Google Scholar, but also on many journal websites) should encourage all academics to consider the utilisation and citation of open access versions of colleagues' work rather than, the seemingly common practice, of looking for the authoritative publication location. This does require a greater commitment to weighing the shape/content of the argument(s) but this is hardly a divergence from standard academic practice. Alternatively, a strategy of signalling relevance and accreditation information (such as Academia.edu's recommendation function perhaps) may offer another path for colleagues seeking markers of quality other than journal publication. In other words, one of the key challenges for supporters of openness is to find ways of delivering the quality-related quick and ready assessments (sign-posts) that previously were delivered via proprietary modes of assuring the origins of academic information and knowledge; finding a model of bounded openness that works widely across the academy may be the 'gamechanger' required for open access to prosper.

As this indicates, rather than an either/or proposition, there is a more fluid set of possibilities, reflecting pragmatic choices between property and openness, with openness acting as a countervailing force balancing excessive claims to property rights. This balance may constrain the more pernicious aspects of rampant actions of the publishing oligopoly through the conjunction of ownership and 'openness' in an ongoing dialectical relationship, each modifying but also depending on the other; here the contending approaches to dealing with open access for academic outputs are not so much a zero sum game, but rather the manner in which the academic community decides which outputs require which form of authority balanced with a desired level of access.

This then suggests, secondly, that within this mixed ecology of publication options, self-publication and blogs will play a major role, with academic literacies in various academic disciplines progressively according particular forums or locations weight of authority and reliability. More importantly, as an academic community we need to be much clearer that open access publications are a benefit both to the research community but also to the intra-institutional prestige economy - we can do this by citing open access work, and by ensuring that what is published in alternative locations is of the highest quality and we draw our peers' attention to it.

All of this indicates:

- Senior colleagues who sit on appointments and promotions committees need to work to normalise open access publication as conveying recognisable academic achievement;

- The new(er) generations of scholars need to continue to expand their use of alternative (open access) communication routes and early non-formalised publication;

- Research centres and other potential repositories of open access work need to be much clearer about their quality assurance for content and process of review;

- Perhaps, most importantly we need to see the appearance of similar work, research or analysis in multiple locations (with different access protocols) not as 'salami slicing' of research but the recognition of the variegated ecology of publishing. 
The key thing is that the future of academic publishing is in the hands of the academic communities it serves and if we in PIR are saddled with high subscription prices and/or constrained access, then in the end we only have ourselves to blame, as we have not done enough to change a system which remains in our control even if those who profit from it have done their best to obscure this fact. The scientific community has recognised this and acted and so should we! 


\section{Bibliography}

Atchison, Amy and Bull, Jonathan (2015) 'Will Open Access Get Me Cited? An Analysis of the Efficacy of Open Access Publishing in Political Science' PS - Political Science and Politics January: 129-137.

Buranyi, Stephen (2017) 'Is the staggeringly profitable business of scientific publishing bad for science?' The Guardian (Long Read) 27 June [available at: https://www.theguardian.com/science/2017/jun/27/profitable-business-scientificpublishing-bad-for-science (22. 10. 2018)]

Carling, Jørgen et al (2018) At the crossroads of open access to research: An assessment of the possible consequences of Plan S for publishing, research quality and research environments Oslo: Peace Research Institute Oslo /Faculty of Social Sciences, University of Oslo

Cochran, Angela (2018) 'Are Mirror Journals a Better Path to the Open Access Flip?' The Scholarly Kitchen (29 October) [available at:

https://scholarlykitchen.sspnet.org/2018/10/29/are-mirror-journals-a-better-path-tothe-open-access-flip/ (01.02.2019)

Cody, Brian (2018) 'Plan S[how me the money]: why academic-led initiatives represent a more equitable, less costly publishing future' LSE Impact Blog (24 October) [available at: http://blogs.Ise.ac.uk/impactofsocialsciences/2018/10/24/planshow-me-the-money-why-academic-led-initiatives-represent-a-more-equitable-lesscostly-publishing-future/ (28.01.2019)]

Costello, Eamon (2019) 'Bronze, free or fourée: an open access commemtary' Science Editing 6, 1: 69-72.

David, Matthew (2017) Sharing: Crime Against Capitalism Cambridge: Polity Press.

Else, Holly (2018) 'Radical plan to end paywalls' Nature Vol.561 (6 September): 1718.

Eve, Martin Paul (2014) Open Access And The Humanities: Contexts, Controversies and the Future Cambridge: Cambridge University Press

Fortson, Danny (2019) 'A Napster moment for ivory towers' Sunday Times (Business section) February 17: 8

Fyfe, Aileen, et al. (2017) Untangling Academic Publishing: a history of the relationship between commercial interests, academic prestige and the circulation of research [ available at: https://doi.org/10.5281/zenodo.546100 (01/08/2018)]

Glassman, Jim (2006) 'Primitive accumulation, accumulation by dispossession, accumulation by 'extra-economic' means' Progress in Human Geography 30, 5: $608-625$ 
Green, Toby (2018) 'We're still failing to deliver open access and solve the serials crisis: to succeed we need a digital transformation of scholarly communication using internet-era principles.' Zenodo http://doi.org/10.5281/zenodo.1410000 (22.10.2018)

Guédon, Jean-Claude et al (2019) (eds) Future of Scholarly Publishing and Scholarly Communication: Report of the Expert Group to the European Commission Brussels: European Commission, Directorate-General for Research and Innovation.

Holmwood, John (2018) 'The expansion of open access is being driven by commercialisation, where private benefit is adopting the mantle of public value' LSE Impact Blog (2 October) [available at:

http://blogs.Ise.ac.uk/impactofsocialsciences/2018/10/02/the-expansion-of-openaccess-is-being-driven-by-commercialisation-where-private-benefit-is-adopting-themantle-of-public-value/ (01.02.2019)]

Kramer, Bianca and Bosman, Jeroen (2018) 'Towards a Plan S gap analysis? (1) Open access potential across disciplines' Innovations in Scholarly Communication (5 December) [available at: https://101innovations.wordpress.com/2018/12/05/oapotential-journals-and-publications-across-disciplines/ (28.01.2019)]

Kwon, Diana (2018) 'Plan S: The Ambitious Initiative to End the Reign of Paywalls' The Scientist (19 December) [available at: https://www.the-scientist.com/newsopinion/plan-s--the-ambitious-initiative-to-end-the-reign-of-paywalls-65231 (28.01.2019)]

Larivière, Vincent, Haustein, Stefanie and Mongeon, Phillippe (2015) 'The Oligopoly of Academic Publishers in the Digital Era' PLOS ONE 106) [available at: http://journals. plos.org/plosone/article?id=10.1371/journal.pone $.0127502 \&$ version $=\mathrm{m}$ eter+at+null\&module $=$ meterLinks\&pgtype=article\&contentld=\&mediald=\&referrer=\&priority=true\&action=click\&co ntentCollection=meter-links-click (22.10.2018)]

May, Christopher (2005) 'The academy's new electronic order? Open source journals and publishing political science' European Political Science 4, 1: 14-24

May, Christopher (2011) 'Bounded Openness: The Future Political Economy of Knowledge Management' European Intellectual Property Review 33, 8: 477-480.

May, Christopher (2013) 'Still Waiting for the New Electronic Order' E-International Relations [available at: http://www.e-ir.info/2013/08/11/still-waiting-for-the-newelectronic-order/ (25.07.2018)]

Merrett, Christopher (2006) 'The expropriation of intellectual capital and the political economy of international academic publishing' Critical Arts, 20, 1: 96-111

Nygaard, Lynn P. (2017) 'Publishing and perishing: an academic literacies framework for investigating research productivity' Studies in Higher Education, 42, 3: $519-532$ 
O'Carrol, Conor et al (2017) (eds) Evaluation of Research Careers fully acknowledging Open Science practices: Rewards, incentives and/or recognition for researchers practicing Open Science Brussels: European Commission, DirectorateGeneral for Research and Innovation20170pen Science and ERA policy

Perelman, Michael (2000) The Invention of Capitalism: Classical Political Economy and the Secret History of Primitive Accumulaton Durham N.C.: Duke University Press.

Phillips, Angus (2009) 'Business models in journal publishing' in: B.Cope and A.Phillips (eds) The Future of the Academic Journal Witney: Chandos Publishing.

Pirie, Ian (2009) 'The Political Economy of Academic Publishing' Historical Materialism 17: 31-60

Sassen, Saskia (2010) 'A Savage Sorting of Winners and Losers: Contemporary Versions of Primitive Accumulation' Globalizations 7, 1-2: 25-50.

Shreeves, Sarah L. (2009) ' "Cannot predict now”: The role of repositories in the future of the journal' in: B.Cope and A.Phillips (eds) The Future of the Academic Journal Witney: Chandos Publishing.

Willinsky, John (2005) 'Scholarly Associations and the Economic Viability of Open Access Publishing' Open Journal System Demonstration Journal 1, 1 [no page numbers] 